\title{
Analisis Keselamatan dan Kesehatan Kerja Menggunakan Metode Hazard And Operability Study (HAZOP) Di PT. XYZ
}

\author{
Muhammad Nur \\ Prodi Teknik Industri, Fakultas Sains dan Teknologi, UIN SUSKA Riau \\ JL.HR. Soebrantas No. 155, Simpang Baru, Panam, Pekanbaru, 28293 \\ Email: veradevani@gmail.com
}

\begin{abstract}
ABSTRAK
PT. XYZ sebuah perusahaan swasta nasional yang bergerak di bidang konstruksi pembuatan aspal untuk jalan raya. Besarnya potensi kecelakaan kerja yang terjadi pada proses pengolahan aspal menyebabkan perusahaan untuk memberikan upaya pengendalian terhadap potensi kecelakaan kerja.Berdasarkan permasalahan tersebut maka dilakukan indentifikasi dan evaluasi masalah-masalah yang mewakili resikoresiko perorangan atau peralatan atau mencegah operasi yang efisien.perhitungan nilai statistik kecelakaan kerja (Accident Rate), potensi bahaya dan sumber bahaya menggunakan metode Frequency Rate, Severity Rate, Safe T-Scoredan Risk Matriks. Yang bertujuan untuk mengindentifikasi jumlah cidera yang menyebabkan tidak bisa bekerja, untuk mengetahui tingkat keparahan dari suatu kecelakaan kerja yang terjadi, untuk menilai tingkat perbedaan antara dua kelompok yang dibandingkan.Apakah perbedaan pada dua kelompok tersebut bermakna atau tidak, dan untuk penetapan matriks resiko kecelakaan kerja itu terjadi.Berdasarkan hasil pengolahan data maka dapat disimpulkan bahwa nilaiFrequency Ratepada tahun 2013 sampai 2015 yaitu sebesar 21 pada setiap 200.000 jam kerja manusia, Severity Rate yaitu sebesar 60 hari pada setiap 200.000 jam kerja manusia, Safe T-Score yaitu 0,51 dan Risk Matriks yaitu tingkat bahaya tinggi. Maka diperlukan perbaikan keselamatan kerja pada proses pengolahan aspal terutama untuk melakukan pengawasan pada pekerja pentingnya APD (Alat Pelindung Diri).
\end{abstract}

Kata Kunci: Accident Rate, Frequency Rate, Risk Matriks, Safe T-Score,Severity Rate

\section{Pendahuluan}

Indonesia sebagai negara berkembang telah berusaha menunjukkan eksistensinya dalam membangun infrastuktur negara.industri berkembang dan tumbuh secara cepat, dan tidak dapat dipungkiri lagi bahwa arus globalisasi membawa pengaruh yang besar bagi dunia industri, khususnya di Indonesia, perkembangan dunia industri juga diiringi dengan perkembangan teknologi, pemanfaatan teknologi disamping memberikan kemudahan dalam proses produksi juga menandung berbagai resiko dan potensi bahaya lainnya. Persaingan industri menuntut perusahaan untuk mengoptimalkan seluruh sumber daya yang mereka miliki, dalam menghasilkan produk berkualitas tinggi, kualitas produk yang dihasilkan tidak terlepas dari peranan sumber daya manusia yang dimiliki perusahaan, sumber daya manusia sebagai tenaga kerja tidak terlepas dari masalahmasalah yang berkaitan dengan Keselamatan dan Kesehatannya sewaktu bekerja. Menurut International Labour Organization (ILO), setiap tahunnya terjadi 1,1 juta kematian yang disebabkanoleh karenapenyakit atau kecelakaan akibat hubungan pekerjaan.

PT. XYZ adalah sebuah perusahaan swasta nasional yang bergerak di bidang konstruksi pembuatan aspal untuk jalan raya.PT. XYZdalam proses pengolahan aspal tidak terlepas dari masalah-masalah yang berkaitan dengan kecelakaan kerja yang banyak terjadi, hal ini menyebabkan konsenkuensi yang merugikan bagi perusahaan. Berdasarkan latar belakang di tersebut, didapatkan rumusan masalah yaitu bagaimana mengetahui potensi kecelakaan kerja serta upaya pengendalian terhadap potensi kecelakaan kerja di PT. XYZ.

Tujuan penelitian yang dilakukan adaah untuk menentukan nilai statistik kecelakaan kerja dengan Frequency Rate, Severity Rate, dan Safe - T Score di PT. XYZ, mengetahui potensi kecelakaan kerja pada proses konstruksi, dan memberikan upaya pengendalian terhadap potensi kecelakaan kerja.

\section{Tinjauan Pustaka}

\section{Definisi, Tujuan, dan Konsep HAZOP (The Hazard and Operability Study)}

The Hazard and Operability Study, HAZOP didefinisikan sebagai. Tujuan penggunaan HAZOP adalah untuk meninjau suatu proses atau operasi pada suatu sistem secara sistematis, untuk menentukan apakah proses penyimpangan dapat mendorong kearah kejadian atau kecelakaan yang tidak diinginkan.

HAZOP secara sistematis mengidentifikasi setiap kemungkinan penyimpangan (deviation) dari 
kondisi operasi yang telah ditetapkan dari suatu plant, mencari berbagai faktor penyebab (cause) yang memungkinkan timbulnya kondisi abnormal tersebut, dan menentukan konsekuensi yang merugikan sebagai akibat terjadinya penyimpangan serta memberikan rekomendasi atau tindakan yang dapat dilakukan untuk mengurangi dampak dari potensi risiko yang telah berhasil diidentifikasi [5].

Istilah terminologi yang dipakai untuk mempermudah pelaksanaan HAZOP antara lain sebagai berikut [5]:

1. Proses

Proses apa yang sedang terjadi atau lokasi dimana proses tersebut berlangsung.

2. Sumber Hazard

Sumber bahaya (hazard) yang ditemukan di lapangan.

3. Deviation (Penyimpangan)

Hal - hal apa saja yang berpotensi untuk menimbulkan risiko.

4. Cause (Penyebab)

Adalah sesuatu yang kemungkinan besar akan mengakibatkan penyimpangan.

5. Consequence (Akibat/Konsekuensi)

Akibat dari deviation yang terjadi yang harus diterima oleh sistem.

6. Action (Tindakan)

Tindakan dibagi menjadi dua kelompok yaitu tindakan yang mengurangi atau menghilangkan akibat (konsekuensi). Sedangkan apa yang terlebih dahulu diputuskan hal ini tidak selalu memungkinkan terutama ketika berhadapan dengan kerusakan peralatan. Namun, pada awalnya selalu diusahakan untuk menyingkirkan penyebabnya dan hanya di bagian mana perlu mengurangi konsekuensi.

7. Severity

Merupakan tingkat keparahan yang diperkirakan dapat terjadi.

8. Likelihood

Adalah kemungkinan terjadinya konsekuensi dengan sistem pengaman yang ada.

9. Risk

Risk atau risiko merupakan nilai risiko yang didapatkan dari kombinasi kemungkinan likelihood dan severity.

\section{Identifikasi Hazard dengan HAZOP Worksheet dan Risk Assesment}

Langkah-langkah untuk melakukan identifikasi Hazard dengan menggunakan HAZOP Worksheet dan Risk Assessment adalah sebagai berikut [5]:

1. Mengetahui urutan proses yang ada pada area penelitian.

2. Mengidentifikasi hazard yang ditemukan pada area penelitian.
3. Melengkapi kriteria yang ada pada HAZOP worksheet dengan urutan sebagai berikut:

a. Mengklasifikasikan hazard yang diketemukan (sumber hazard dan frekuensi temuan hazard).

b. Mendeskripsikan deviation atau penyimpangan yang terjadi selama proses operasi.

c. Mendeskripsikan penyebab terjadinya penyimpangan (cause)

d. Mendeskripsikan apa yang dapat ditimbulkan dari penyimpangan tersebut (consequences).

e. Menentukan action atau tindakan sementara yang dapat dilakukan.

f. Menilai risiko (risk assessment) yang timbul dengan mendefinisikan kriteria likelihood dan consequences (severity). Kriteria likelihood(seperti pada Tabel 2.1) yang digunakan adalah frekuensi dimana dalam perhitunganya secara kuantitatif berdasarkan data atau record perusahaan selama kurun waktu tertentu. Kriteria consequences (severity) yang digunakan adalah akibat apa yang akan diterima pekerja yang didefinisikan secara kualitatif dan mempertimbangkan hari kerja yang hilang (seperti pada Tabel 2)

g. Merancang perbaikan untuk risiko yang memiliki level "Ekstrim", kemudian melakukan rekomendasi perbaikan untuk proses

Tabel 1 dan 2 menunjukkan kriteria Likelihood dan Kriteria Consequences/Severity [9].

Tabel 1 Kriteria Likelihood

\begin{tabular}{|c|c|c|c|}
\hline \multicolumn{4}{|c|}{ Likelihood } \\
\hline \multirow{2}{*}{ Level } & \multirow{2}{*}{ Criteria } & \multicolumn{2}{|c|}{ Description } \\
\hline & & Kualitatif & Kuantitatif \\
\hline 1 & $\begin{array}{l}\text { Jarang } \\
\text { terjadi }\end{array}$ & $\begin{array}{l}\text { Dapat dipikirkan } \\
\text { tetapi tidak hanya } \\
\text { saat keadaan yang } \\
\text { ekstrim }\end{array}$ & $\begin{array}{l}\text { Kurang dari } \\
1 \text { kali per } 10 \\
\text { tahun }\end{array}$ \\
\hline 2 & $\begin{array}{l}\text { Kemungki } \\
\text { nan kecil }\end{array}$ & $\begin{array}{l}\text { Belum terjadi tetapi } \\
\text { bisa muncul / terjadi } \\
\text { pada suatu waktu }\end{array}$ & $\begin{array}{l}\text { Terjadi } 1 \\
\text { kali per } 10 \\
\text { tahun }\end{array}$ \\
\hline 3 & Mungkin & $\begin{array}{l}\text { Seharusnya terjadi } \\
\text { dan mungkin telah } \\
\text { terjadi / muncul } \\
\text { disini atau di tempat } \\
\text { lain }\end{array}$ & $\begin{array}{l}1 \text { kali per } 5 \\
\text { tahun sampai } \\
1 \text { kali per } \\
\text { tahun }\end{array}$ \\
\hline 4 & $\begin{array}{l}\text { Kemungki } \\
\text { nan besar }\end{array}$ & $\begin{array}{l}\text { Dapat terjadi dengan } \\
\text { mudah, mungkin } \\
\text { muncul dalam } \\
\text { keadaan yang paling } \\
\text { banyak terjadi }\end{array}$ & $\begin{array}{l}\text { Lebih dari } 1 \\
\text { kali per } \\
\text { tahun hingga } \\
1 \text { kali } \\
\text { perbulan }\end{array}$ \\
\hline
\end{tabular}




\begin{tabular}{llll}
\hline 5 & Hampir & $\begin{array}{l}\text { Sering terjadi, } \\
\text { diharapkan muncul } \\
\text { dalam keadaan yang } \\
\text { paling banyak } \\
\text { terjadi }\end{array}$ & $\begin{array}{l}\text { Lebih dari 1 } \\
\text { kali per } \\
\text { bulan }\end{array}$ \\
\hline
\end{tabular}

Kriteria Likelihooddigunakan untuk frekuensi dimana dalam perhitunganya secara kuantitatif berdasarkan data atau record perusahaan selama kurun waktu tertentu.

Tabel 2 Kriteria Consequences/Severity

\begin{tabular}{|c|c|c|c|}
\hline \multicolumn{4}{|c|}{ Consequences/Severity } \\
\hline Level & Uraian & $\begin{array}{c}\text { Keparahan } \\
\text { Cidera }\end{array}$ & Hari Kerja \\
\hline 1 & $\begin{array}{l}\text { Tidak } \\
\text { signifikan }\end{array}$ & $\begin{array}{l}\text { Kejadian tidak } \\
\text { menimbulkan } \\
\text { kerugian atau } \\
\text { cedera pada } \\
\text { manusia }\end{array}$ & $\begin{array}{l}\text { Tidak } \\
\text { menyebabk } \\
\text { an } \\
\text { kehilangan } \\
\text { hari kerja }\end{array}$ \\
\hline 2 & Kecil & $\begin{array}{l}\text { Menimbulkan } \\
\text { cedera ringan, } \\
\text { kerugian kecildan } \\
\text { tidak } \\
\text { menimbulkan } \\
\text { dampak serius } \\
\text { terhadap } \\
\text { kelangsungan } \\
\text { bisnis }\end{array}$ & $\begin{array}{l}\text { Masih } \\
\text { dapat } \\
\text { bekerja } \\
\text { pada hari / } \\
\text { shift yang } \\
\text { sama }\end{array}$ \\
\hline 3 & Sedang & $\begin{array}{l}\text { Cedera berat dan } \\
\text { dirawat dirumah } \\
\text { sakit, tidak } \\
\text { menimbulkan } \\
\text { cacat tetap, } \\
\text { kerugian finansial } \\
\text { sedang }\end{array}$ & $\begin{array}{l}\text { Kehilangan } \\
\text { hari kerja } \\
\text { dibawah } 3 \\
\text { hari }\end{array}$ \\
\hline 4 & Berat & $\begin{array}{l}\text { Menimbulkan } \\
\text { cedera parah dan } \\
\text { cacat tetap dan } \\
\text { kerugian finansial } \\
\text { besar serta } \\
\text { menimbulkan } \\
\text { dampak serius } \\
\text { terhadap } \\
\text { kelangsungan } \\
\text { usaha }\end{array}$ & $\begin{array}{l}\text { Kehilangan } \\
\text { hari kerja } 3 \\
\text { hari atau } \\
\text { lebih }\end{array}$ \\
\hline 5 & Bencana & $\begin{array}{l}\text { Mengakibatkan } \\
\text { korban meninggal } \\
\text { dan kerugian } \\
\text { parah bahkan } \\
\text { dapat } \\
\text { menghentikan } \\
\text { kegiatan usaha } \\
\text { selamanya }\end{array}$ & $\begin{array}{l}\text { Kehilangan } \\
\text { hari kerja } \\
\text { selamanya }\end{array}$ \\
\hline
\end{tabular}

Kriteria consequences (severity) yang digunakan adalah akibat apa yang akan diterima pekerja yang didefinisikan secara kualitatif dan mempertimbangkan hari kerja yang hilang.

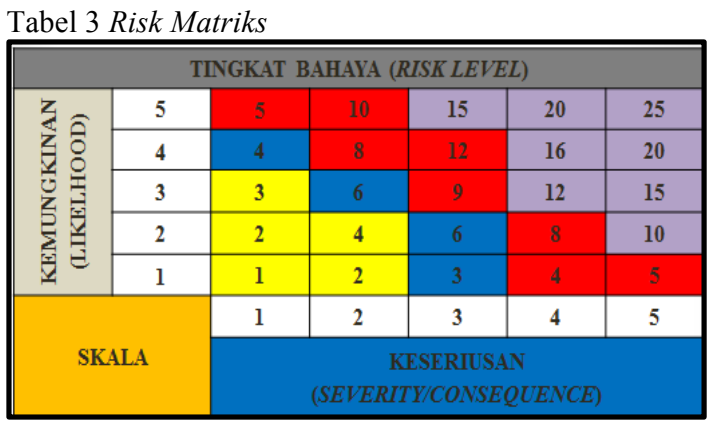

Keterangan :

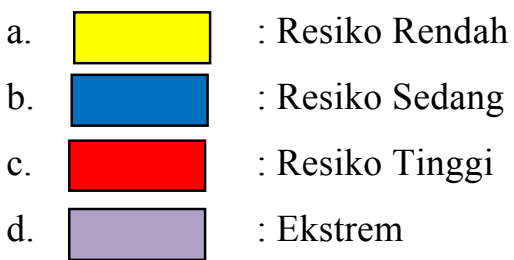

Contoh perhitungan :

Nilai Likelihood $(\mathrm{L}) \quad=4$

Nilai Concequences $(\mathrm{C}) \quad=4$

$\mathrm{L} \times \mathrm{C}=16$ (Terletak di warna ungu, sehingga digolongan kategori "Ekstrim".

Tabel 4 Keterangan Matriks Resiko

\begin{tabular}{ll}
\hline & $\begin{array}{l}\text { Kegiatan tidak boleh dilaksanakan } \\
\text { atau dilakukan sampai resiko telah } \\
\text { direduksi. }\end{array}$ \\
Ekstrim & $\begin{array}{l}\text { Jika tidak ada kemungkinan untuk } \\
\text { mereduksi resiko dengan sumber } \\
\text { daya yang terbatas, maka } \\
\text { pekerjaan tidak dapat } \\
\text { dilaksanakan. }\end{array}$ \\
\hline \multirow{5}{*}{ Kegiatan tidak boleh dilaksanakan } \\
atau dilakukan sampai resiko telah \\
direduksi. \\
Perlu dipertimbangkan sumber \\
daya yang dialokasikan untuk \\
mereduksi resiko. \\
Apabila terdapat dalam \\
pelaksanaan pekerjaan yang masih \\
berlangsung, maka tidakan harus \\
segera dilakukan.
\end{tabular}




\section{Metode Penelitian}

Pada penelitian ini, data diperoleh melalui survey di lapangan dan studi literatur. Data yang digunakan adalah data primer berupa data potensi kecelakaan dari karyawan, potensi kecelakaan kerja pada saat menggunakan mesin-mesin, dan potensi kecelakaan kerja kerja pada saat berada di lingkungan tempat kerja dan data sekunder berupa profil perusahaan dan struktur organisasi perusahaan yang ada di PT. XYZ. Adapun langkahlangkah dalam pengolahan data dalam penyelesaian K3 adalah:

1. Menghitung nilai Likelihood berdasarkan kriteria tertentu

2. Mengetahui nilai konsekuensi berdasarkan referensi

3. Langkah selanjutnya yaitu menentukan matriks resiko sehingga didapatkan nilai potensi kecelakaan kerja yang bernilai ekstrim.

\section{Hasil dan Pembahasan}

Data yang diolah adalah data kecelakaan kerja dari bulan Juli 2013 hingga Desember 2015 dimana nantinya hasil pengolahan data tersebut dihitung untuk menentukan Risk Matriks.

\section{Statistik Kecelakaan Kerja}

Berikut data kecelakaan kerjaPT. XYZ tahun 2013-2015:

Tabel 5 Data Kecelakaan Kerja PT. XYZ Tahun 20132015

\begin{tabular}{|c|c|c|c|c|c|}
\hline Tahun & $\begin{array}{l}\text { Jumlah } \\
\text { karyaw } \\
\text { an }\end{array}$ & $\begin{array}{l}\text { Total } \\
\text { accident }\end{array}$ & $\begin{array}{l}\text { Hari } \\
\text { yang } \\
\text { hilan } \\
\text { g } \\
\end{array}$ & $\begin{array}{l}\text { Man } \\
\text { hours } \\
\text { APR }\end{array}$ & $\begin{array}{l}\text { Kerugian } \\
\text { perusahaa } \\
\text { n } \\
\text { (Rp) }\end{array}$ \\
\hline 2013 & 9 & 4 & 8 & 64 & $\begin{array}{l}\text { Rp. } \\
4.200 .000\end{array}$ \\
\hline 2014 & 12 & 6 & 12 & 88 & $\begin{array}{l}\text { Rp. } \\
6.400 .000\end{array}$ \\
\hline 2015 & 18 & 14 & 19 & 136 & $\begin{array}{l}\text { Rp. } \\
9.800 .000\end{array}$ \\
\hline
\end{tabular}

\section{Metode Frequency Rate}

Frequency Ratedigunakan untuk mengidentifikasi jumlah cidera yang menyebabkan tidak bisa bekerja per sejuta orang pekerja.

$$
\text { FR }=\frac{\text { Banyaknya Kecelakaan X 200.000 }}{\text { Total Jam Kerja Manusia }}
$$

Hasil nya pada tahun 2013 frequency rate nya adalah 12,5 dengan accident / years berjumlah 13 pada setiap 200.000 jam kerja manusia. Pada tahun 2014 frequency rate nya adalah 13,6 dengan accident / years berjumlah 14 pada setiap 200.000 jam kerja manusia. Kemudian pada tahun 2015 frequency rate nya adalah 20,5 terjadi peningkatan kecelakaan kerja secara signifikan dengan accident
/ years berjumlah 21 pada setiap 200.000 jam kerja manusia.

\section{Metode Severity Rate}

Merupakan perhitungan untuk mengetahui tingkat keparahan dari suatu kecelakaan kerja yang terjadi.

$$
\mathrm{SR}=\frac{\text { Total Hari Kerja Hilang X } 200.000}{\text { Total Jam Kerja Manusia }}
$$

Hasil nya pada tahun 2013 severity rate nya adalah 25,0 dengan Lost Day Cause Accident/ Years berjumlah 25 hari pada setiap 200.000 jam kerja manusia. Pada tahun 2014 severity rate nya adalah 27,2 dengan Lost Day Cause Accident/ Years berjumlah 28 hari pada setiap 200.000 jam kerja manusia. Kemudian pada tahun 2015 severity rate nya adalah 59,3 terjadi peningkatan hilangnya waktu kerja secara signifikan dengan Lost Day Cause Accident/ Years berjumlah 60 hari pada setiap 200.000 jam kerja manusia.

\section{Metode Safe-T Score}

Nilai indikator untuk menilai tingkat perbedaan antara dua kelompok yang dibandingkan.Apakah perbedaan pada dua kelompok tersebut bermakna atau tidak.Dalam statistik biasanya disebut sebagai $t$-test.

Safe - T Score $=\frac{\text { Frekuensi Rate Sekarang X Frekuensi Rate Sebelumnya }}{\text { Frekuensi }}$

Hasil nya pada tahun 2013-2014 Safe - T Score nya adalah -0,09 yang dikategorikan baik. Kemudian pada tahun 2014-2015 Safe - T Score nya adalah 0,51 yang dikategorikan baik.

\section{Potensi Bahaya dan Sumber Bahaya}

Berdasarkan hasil observasi lapangan di PT. PT. XYZ terdapat beberapa potensi bahaya yang diakibatkan pada proses pembuatan aspal. Potensi bahaya tersebut digolongkan atas 3 faktor yaitu faktor manusia atau pekerja, faktor bahaya pada proses pembuatan aspal dan faktor bahaya pada pengangkutan material.

\begin{tabular}{|c|c|c|c|}
\hline No & Potensi Bahaya & Sumber Bahaya & $\begin{array}{l}\text { Jumlah } \\
\text { Temuan }\end{array}$ \\
\hline 1 & Sikap Pekeja & & 6 \\
\hline \multirow{6}{*}{2} & \multirow{6}{*}{ Pengolahan Aspal } & Kebisingan & 3 \\
\hline & & \begin{tabular}{|l} 
Lalu Lintas Alat Berat \\
\end{tabular} & 4 \\
\hline & & Serphan Material di Area Kerja & 2 \\
\hline & & Debu & 3 \\
\hline & & Area Penyimpanan Aspal Cair & 2 \\
\hline & & Asap & 1 \\
\hline 3 & Pengangkutan Matenial & Area Pengangkutan Material & 3 \\
\hline \multicolumn{3}{|c|}{ Total } & 24 \\
\hline
\end{tabular}

Tabel 6 Potensi Bahaya 


\section{Penilaian Resiko}

Hasil observasi lapangan dari 24 temuan potensi bahaya kemudian digolongkan berdasarkan jenis sumbernya menjadi 8 sumber bahaya antara lain : sikap pekerja, kebisingan, lalu lintas alat berat, serpihan material di area kerja, debu, area penyimpanan aspal cair, asap dan area pengangkutan material. Setelah itu menentukan tingkat keparahan atau perkingan (risk level) dengan mempertimbangkan kriteria resiko Likelihood (L) dengan Severity atau Concequences (C). Dari hasil wawancara yang dilakukan, maka jumlah tingkat bahaya kecelakaan kerja yang diklasifikasikan terhadap nilai Likelihood (L) dengan Concequences (C) sesuai dengan peluang dan resiko tingkat keparahan. Penetapan nilai Likelihood (L) dan Concequences (C) adalah sebagai berikut :

Tabel 7 Penetapan Nilai Likelihood dan Concequences

\begin{tabular}{|c|c|c|c|}
\hline No & $\begin{array}{l}\text { Sumber } \\
\text { Hazard }\end{array}$ & $\begin{array}{l}\text { Likelihood } \\
\text { (L) }\end{array}$ & $\begin{array}{c}\text { Concequences } \\
\text { (C) }\end{array}$ \\
\hline 1 & Sikap Pekerja & 5 & 4 \\
\hline 2 & Kebisingan & 4 & 3 \\
\hline 3 & $\begin{array}{l}\text { Lalu Lintas Alat } \\
\text { Berat }\end{array}$ & 4 & 4 \\
\hline 4 & $\begin{array}{l}\text { Serpihan } \\
\text { Material Area } \\
\text { Kerja }\end{array}$ & 3 & 2 \\
\hline 5 & Debu & 3 & 2 \\
\hline 6 & $\begin{array}{l}\text { Area } \\
\text { Penyimpanan } \\
\text { Aspal Cair }\end{array}$ & 1 & 4 \\
\hline 7 & Asap & 4 & 3 \\
\hline 8 & $\begin{array}{l}\text { Area } \\
\text { Pengangkutan } \\
\text { Material }\end{array}$ & 4 & 3 \\
\hline
\end{tabular}

\section{Penetapan Matriks Resiko}

Tabel 8 Penetapan Matriks Resiko

\begin{tabular}{|c|l|c|c|c|c|c|}
\hline No & \multicolumn{1}{|c|}{ Sumber Hazard } & L & C & Lx C & Warna & Risk Level \\
\hline 1 & Sikap Pekerja & 5 & 4 & 20 & & Ekstrim \\
\hline 2 & Kebisingan & 4 & 3 & 12 & & Tinggi \\
\hline 3 & Lalu Lintas Alat Berat & 4 & 4 & 16 & & Ekstrim \\
\hline 4 & $\begin{array}{l}\text { Serpihan Material Area } \\
\text { Kerja }\end{array}$ & 3 & 2 & 6 & & Sedang \\
\hline 5 & Debu & 3 & 2 & 6 & & Sedang \\
\hline 6 & $\begin{array}{l}\text { Area Penyimpanan } \\
\text { Aspal Cair }\end{array}$ & 1 & 4 & 4 & & Tinggi \\
\hline 7 & Asap & 4 & 3 & 12 & & Tinggi \\
\hline 8 & $\begin{array}{l}\text { Area Pengangkutan } \\
\text { Material }\end{array}$ & 4 & 3 & 12 & & Tinggi \\
\hline
\end{tabular}

Warna yang ditetapkan pada matriks resiko sesuai dengan tabel risk matriks yang telah ditentukan.

\section{Analisa Perbaikan "Sikap Pekerja"}

Melakukan pengawasan terhadap para karyawan sehingga pekerja tidak lagi bekerja sesuai keinginannya tetapi sesuai dengan standard yang ditetapkan selain itu pelatihan tentang $\mathrm{K} 3$ juga perlu dilakukan terutama yang berhubungan dengan penggunaan APD sehingga pekerja menjadi lebih aman dalam bekerja.Sebaiknya jadwal pelatihan K3 tentang penggunaan APD yang akan diselenggarakan oleh pihak manajemen secara rutin yaitu 1 bulan sekali pada minggu pertama dan pelaksanaannya dilaksanakan sebelum pekerja mulai bekerja pada hari dan shift masing-masing sehingga hasil dari pelatihan tersebut dapat langsung diaplikasikan oleh pekerja. Bagi para pekerja yang tidak dapat menghadiri pelatihan akan dikenakan sanksi. Salah satu cara yang dapat dilakukan untuk pengontrolan para karyawan di PT. XYZ adalah dengan membuat lembar kontrol pelanggaran penggunaan APD. Karena dengan membuat lembar kontrol pelanggaran penggunaan APD, Koordinator Unit dapat mengawasi pekerja agar selalu disiplin menggunakan APD sesuai dengan kegiatan yang dilakukan oleh pekerja di area kerja. Apabila ada pekerja yang melanggar, Koordinator Unit berhak mencatat pelanggaran tersebut dan menyerahkan hasil lembar kontrol setiap 1 minggu sekali ke bagian Industrial Safety yang kemudian pelanggaran tersebut akan dibahas di kegiatan Safety Talk.

\section{Analisa Perbaikan "Lalu Lintas Alat Berat"}

Pengendalian risiko berupa eliminasi (menghilangkan sumber bahaya) dapat diterapkan untuk sumber hazard ini dengan cara segera memperbaiki atau memperbaiki kondisi jalan yang rusak yaitu dengan memberikan pembatas jalan, memberikan rambu-rambu tentang jalan yang curam serta jika memungkinkan melakukan penimbunan sehingga kondisi jalan tidak terlalu curam. Setelah perbaikan dilakukan, pihak manajemen harus terus mengontrol kondisi jalan secara rutin (setiap hari) di area pabrik produksi aspal agar lalu lintas alat berat selalu dalam keadaan baik.

\section{Kesimpulan}

Berdasarkan tujuan yang telah dijelaskan pada penelitian ini, maka kesimpulan pada penelitian ini yaitu:

1. Hasil statistik kecelakaan kerja pada PT. XYZ. a. Perhitungan Metode Frequency Rate (FR) 
Berdasarkan hasil perhitungan nilai statistik kecelakaan kerja dengan menggunakan Metode Frequency Rate dari tahun 2013 sampai dengan tahun 2015 didapatkan bahwa pada tahun 2015 merupakan nilai frequencyrate tertinggi dengan jumlah accident sebanyak 21 accident/year. Sedangkan nilai frequency rate yang terendah terdapat pada tahun 2013 dengan jumlah accident sebanyak 13 accident/year.

b. Perhitungan Metode Severity Rate (SR)

Berdasarkan hasil dari perhitungan nilai statistik kecelakaan kerja dengan menggunakan Metode Severity Rate dari tahun 2013 sampai dengan tahun 2015 didapatkan pada tahun 2015 merupakan nilai severity rate terbanyak atau hilangnya hari kerja akibat dari kecelakaan kerja yaitu 60 Lost Day Cause Accident/Year. Sedangkan nilai severity rate terendah ialah pada tahun 2013 yaitu sebesar 26 Lost Day Cause Accident/Year.

c. Perhitungan Metode Safe-T Score

Berdasarkan hasil perhitungan dengan Metode Safe-T Score diketahui bahwa besar Safe-T Score dari tahun 2013 sampai dengan 2015 ialah $<=-2$ yang artinya menunjukkan membaiknya performance ataupun kinerja $\mathrm{K} 3$, atau ada sesuatu yang baik yang perlu dipertahankan.

2. Potensi kecelakaan kerja pada proses produksi aspal

Potensi pada sikap pekerja tidak memenuhi persyaratan standard dalam keselamatan kerja dan prosedur bekerja yang baik.Potensi pada lalu lintas alat berat proses konstruksi yaitu tidak adanya rambu - rambu untuk kondisi lalu lintas alat berat yang cukup berbahaya.

3. Upaya pengendalian terhadap potensi kecelakaan kerja

a. Melakukan pengawasan terhadap para karyawan serta pelatihan tentang pentingnya pengendalian terhadap potensi kecelakaan kerja adalah APD

b. Memberikan rambu-rambu tentang kondisi jalan serta pengontrolan kondisi jalan secara teratur

\section{Daftar Pustaka}

[1] Bennet N.B Silalahi dan Rumondang Silalahi,1995.Manajemen Keselamatan dan Kesehatan Kerja. Jakarta: PT Pustaka Binaman Pressindo.

[2] Chomiarti, Dian. 2008. Analisis Keselamatan Dan Kesehatan Kerja Berbasis Perilaku Pada Pekerja Konstruksi (Studi Kasus: Pt. Wahana
Karsa Swandiri). Tugas Akhir Teknik Industri Fakultas Sains dan Teknologi.

[3] Efranto, dkk. 2013. Analisis Potensi Bahaya Serta Rekomendasi Perbaikan Dengan Metode Hazard and Operability Study (Hazop) Melalui Perangkingan OHS Risk Assessment and Control. Program Studi Teknik Industri Fakultas Teknik Universitas Brawijaya

[4] Peraturan Departmen Tenaga Kerja dan Transmigrasi No: PER.05/MEN/1996 tentang Sistem Manajemen Kesehatan dan Keselamatan Kerja.

[5] Pujiono, dkk. 2013. Analisis Potensi Bahaya Serta Rekomendasi Perbaikan Dengan Metode Hazard And Operability Study (HAZOP) Melalui Perangkingan Ohs Risk Assessment And Control. Jurnal Teknik Industri Fakultas Teknik Universitas Brawijaya.

[6] Ramli, Soehatman. 2010. Pedoman Praktis Manajemen Resiko dalam Perspektif K3 OHS Risk Management. Jakarta: PT. Dian Rakyat.

[7] Suma'mur P.K., 1989, Kesehatan Kerja dan Pencegahan Kecelakaan Kerja, Jakarta: CV. Haji Masagung.

[8] Syukri, Sahab. 1997. Teknik Manajemen Keselamatan dan Kesehatan Kerja. Jakarta: Bima Sumber Daya Manusia.

[9] UNSW Health and Safety (2008). Risk Management Program. Canberra: University of New South Wales. http://www.ohs.unsw.edu.au/ohsriskmanageme nt/index.html. 